\title{
Appendix 3 Time commitments of regional politicians
}

Table A3.1 Time commitments (hours per week) by type of politician in the Catalan Parliament $(n=43)$

\begin{tabular}{lcccc}
\hline Type of politician & mandate & $\begin{array}{c}\text { Other } \\
\text { political } \\
\text { activities }\end{array}$ & $\begin{array}{c}\text { Local } \\
\text { political } \\
\text { occupation }\end{array}$ & $\begin{array}{c}\text { Non- } \\
\text { political } \\
\text { activity }\end{array}$ \\
\hline Professional parliamentarians & & & & \\
$n$ & 20 & 20 & 20 & 20 \\
Average & 34.8 & 13.8 & 1.5 & 0.3 \\
Median & 32.5 & 15.0 & 0 & 0 \\
Minimum & 18.0 & 0 & 0 & 0 \\
Maximum & 60.0 & 35.0 & 15.0 & 5.0 \\
Professional politicians & & & & \\
$n$ & 10 & 10 & 10 & 10 \\
Average & 21.5 & 30.3 & 0 & 0.3 \\
Median & 20.0 & 31.3 & 0 & 0.0 \\
Minimum & 12.0 & 20.0 & 0 & 0.0 \\
Maximum & 30.0 & 36.0 & 0 & 3.0 \\
Professional local politicians & & & & \\
$n$ & 6 & 6 & 6 & 6 \\
Average & 18.4 & 6.2 & 35.0 & 0 \\
Median & 18.7 & 5.0 & 30.0 & 0 \\
Minimum & 8.0 & 0 & 20.0 & 0 \\
Maximum & 30.0 & 15.0 & 60.0 & 0 \\
Semi-professional politicians & & & & \\
$n$ & 7 & 7 & 7 & 7 \\
Average & 30.0 & 8.9 & 0 & 15.0 \\
Median & 30.0 & 10.0 & 0 & 10.0 \\
Minimum & 20.0 & 0 & 0 & 10.0 \\
Maximum & 40.0 & 20.0 & 0 & 25.0 \\
\hline
\end{tabular}

Source: Author's survey. 
Table A3.2 Time commitments (hours per week) of MSPs in the Scottish

Parliament $(n=43)$

\begin{tabular}{lccc}
\hline & Mandate & Other political & Non-political \\
\hline$n$ & 43 & 43 & 43 \\
Average & 59.0 & 6.8 & 0.6 \\
Median & 60 & 5 & 0 \\
Minimum & 40 & 0 & 0 \\
Maximum & 112 & 30 & 10
\end{tabular}

Source: Author's survey.

Note: MSPs all fall into the professional parliamentarians type. 